\title{
POSITIVE INOTROPIC AND CHRONOTROPIC EFFECTS OF 8-SUBSTITUTED DERIVATIVES OF 3', 5'-CYCLIC AMP
}

\author{
Issei MATSUBARA and Shoichi IMAI \\ Department of Pharmacology, Niigata University School of Medicine, \\ Niigata 951, Japan \\ Accepted May 19, 1975
}

Muneyama et al. $(1971)^{1)}$ reported that several 8-substituted derivatives of 3', 5'-cyclic AMP (cyclic AMP) are more effective than cyclic AMP itself in activating the protein kinase isolated and purified from bovine brain. According to these authors, these compounds are extremely resistant to hydrolysis by rabbit kidney cyclic AMP phosphodiesterase. In fact, they reported, several of these analogs are capable of inhibiting a cyclic AMP phosphodiesterase to a greater extent than theophylline. These findings prompted us to study the biologic effects of these compounds, since they may prove to be useful pharmacological agents. In the present communication, the effects of several 8-substituted derivatives of cyclic AMP on the isolated atrial muscle will be described.

Albino guinea pigs of either sex weighing between $300-550 \mathrm{~g}$ were sacrificed by a blow on the head. The atria were quickly excised, cleaned free of excess tissues and were divided into the right and the left halves. The right atrium, which retained spontaneous rhythm, was used as a whole to assess the chronotropic action of the drugs. The initial resting tension was set at $0.2-0.3 \mathrm{~g}$, and the rate of the spontaneous contraction of this preparation was recorded on an ink-writing oscillograph by means of a linearly-recording tachograph (Nihon Kohden RT-5). The left atrium was used to evaluate the inotropic effect. This preparation was stimulated electrically by a square-wave pulse stimulator (Nihon Kohden MSE-40) at the frequency of $1 \mathrm{~Hz}$ with voltages approx. $30 \%$ above the threshold (duration $=1 \mathrm{msec}$ ). The resting tension of the preparation was kept at $0.2 \mathrm{~g}$ throughout the course of the experiment. Atrial preparations were mounted in a $20 \mathrm{ml}$ organ bath and their contractile tension was recorded on an ink-writing oscillograph with a strain-gauge transducer and a carrier-amplifier. The bathing solution used was a Krebs-Henseleit's solution of the following composition: $\mathrm{NaCl} 118 \mathrm{mM}, \mathrm{KCl} 4.7 \mathrm{mM}, \mathrm{CaCl}_{2} 2.5 \mathrm{mM}, \mathrm{NaHCO}_{3} 24.9 \mathrm{mM}$, $\mathrm{MgSO}_{4} 1.2 \mathrm{mM}, \mathrm{KH}_{2} \mathrm{PO}_{4} 1.2 \mathrm{mM}$ and glucose $12 \mathrm{mM}$. The temperature of the solution was maintained at $32-1{ }^{\circ} \mathrm{C}$. The solution was aerated with a mixture of $95 \% \mathrm{O}_{2}$ and $5 \% \mathrm{CO}_{2}$. After dissection all preparations were allowed to equilibrate for one hour prior to addition of any drugs. The drugs used were as follows: 8-thio cyclic AMP, 8-oxy cyclic AMP, 8-amino cyclic AMP, 8-bromo cyclic AMP, 8-azido cyclic AMP, 8-methylthio cyclic AMP, 8-benzylthio cyclic AMP, 8-methoxy cyclic AMP, 8-dimethylamino cyclic AMP, and $\mathrm{N}^{\hat{}}$, 
2'-O dibutyryl cyclic AMP. All the 8-substituted cyclic AMP used were kindly supplied as free acid by the Seishin Pharmaceutical Co., Tokyo, Japan. Because of the low solubility of these compounds, they were dissolved in Krebs-Henseleit's solution and administered to the preparation by replacing $2-5 \mathrm{ml}$ of the bathing solution. $\mathrm{N}^{6}, 2^{\prime}$-O dibutyryl cyclic AMP was supplied by the Dai-ichi Pharmaceutical Co., Tokyo, Japan, as Na salt, and was dissolved in redistilled $\mathrm{H}_{2} \mathrm{O}$. It was injected into the bathing solution (volume: Icss than $1.6 \mathrm{ml}$ ). Table 1 summarizes the results obtained with nine 8 -substituted derivatives of cyclic

TABLE 1. Cardiac actions of 8-substituted cyclic AMP derivatives $(0.5 \mathrm{mg} / \mathrm{ml})$ in guinea pig's atria

\begin{tabular}{|c|c|c|c|}
\hline Chemical structure & $R=$ & $\begin{array}{c}\text { Positive } \\
\text { chronotropic }\end{array}$ & $\begin{array}{l}\text { Posilive } \\
\text { inotropic }\end{array}$ \\
\hline & SH & $79.5 \pm 4.2$ & $134.4 \pm 20.3$ \\
\hline & $\mathrm{OH}$ & $84.7 \pm 0.3$ & $119.3 \pm 12.3$ \\
\hline & $\mathrm{SCH}_{2} \mathrm{C}_{6} \mathrm{H}_{5}$ & $84.2=6.7$ & $89.9 \pm 3.6$ \\
\hline & $N_{3}$ & $68.4: 2.1$ & $47.9 \pm 7.6$ \\
\hline & $\mathrm{SCH}_{3}$ & $59.8 \perp 3.9$ & $40.2=3.3$ \\
\hline & $\mathrm{OCH}_{3}$ & $56.2 \pm 3.1$ & $28.9 \perp 9.7$ \\
\hline $0 \rightarrow p-0$ & $\mathrm{~N}\left(\mathrm{CH}_{3}\right)_{2}$ & $31.8+12.8$ & $20.1 \pm 1.1$ \\
\hline & $\mathrm{Br}$ & $62.3 \pm 6.2$ & $27.9+11.6$ \\
\hline OH & $\mathrm{NH}_{2}$ & variable* & variable ${ }^{*}$ \\
\hline
\end{tabular}

$\%$ of the maximum response to 1 sp. Mean + S.E. $(n=4)$

* Either a positive (2/4) or a negative effect was obscrved (2/4).

AMP. Eight derivatives produced definite positive inotropic and chronotropic effects. The effects were dose-dependent at a range of $10^{-4}-5 \times 10^{-4} \mathrm{~g} / \mathrm{ml}$ and fully reversible. With some compounds, the positive inotropic effects surpassed the maximum effects obtainable with $10^{-7} \mathrm{M}$ of isoproterenol. To give some idea about the time course of the effects of 8 -substituted cyclic AMP, the positive inotropic effect of $0.5 \mathrm{mg} / \mathrm{ml}$ of 8 -SH cyclic AMP is depicted in Fig. 1 in comparison with that of $2 \mathrm{mg} / \mathrm{ml}$ dibutyryl cyclic AMP. Just like the positive inotropic effect of dibutyryl cyclic AMP, the effect of the 8-SH derivative evolved slowly, taking more than 20 minutes to attain a steady maximum. Because of the low solubility of $8-\mathrm{SH}$ derivative, we did not employ a higher concentration of this compound. However, unlike dibutyryl cyclic AMP, which invariably produced initial negative effects, as shown in Fig. 1, such a negative phase was only rarely observed in the case of 8 -substituted compound.

As a preliminary step in searching the underlying mechanism of the positive inotropic and chronotropic effects of 8-substituted cyclic AMP, we examined the effects of pretreatment of the preparation with aminophylline on the positive inotropic effects of thesc compounds. As representative 8-substituted derivatives, we used 8-SH and 8-SCH${ }_{2} \mathrm{C}_{6} \mathrm{H}_{5}$ compounds.

Pretreatment of the preparation with $10^{-4} \mathrm{M}$ of aminophylline for 60 min resulted in a potentiation of the positive inotropic effects of these two derivatives as well as those of dibutyryl cyclic AMP. These findings, if taken together with those of Muneyama et al. 


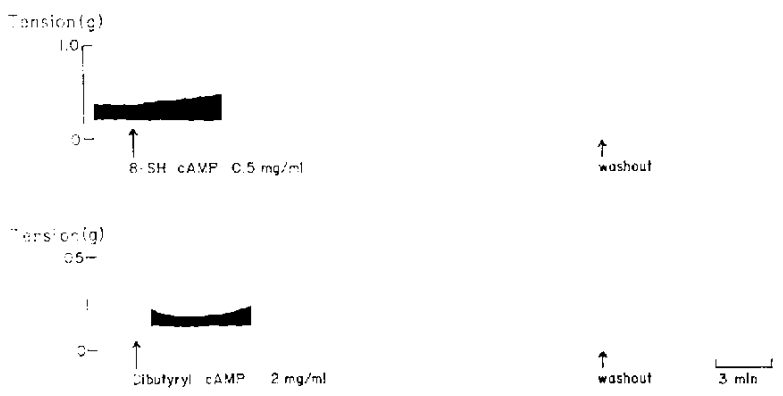

FIG. 1. Positive inorropic effects of 8-SH cyclic AMP (8-SH cAMP) and dibutyryl cyclic AMP (Dibutyryl cAMP) as studied in the isolated left atria of the guinea pig.

Atria were driven with square-wave pulses of an electronic stimulator (Frequency: 1 liz; Duration: 1 msec).

which indicate that 8 -substituted derivatives themselves (except $8-\mathrm{NH}_{2}$ cyclic AMP) are resistant to degradation by cyclic AMP phosphodiesterase, may imply that the positive inotropic (and possibly chronotropic) effects of 8 -substituted derivatives are due to an accumulation of cyclic AMP within the cell, as is postulated in the case of dibutyryl cyclic $A M P^{2)-5)}$. However, since the potentiation by aminophylline of the effects of 8 -substituted compounds was not so remarkable as that of dibutyryl cyclic AMP, the possibility that 8 -substituted compounds exerted their effects through inhibition of the phosphodiesterase cannot be ruled out. At any rate, we now have several more derivatives of cyclic AMP which can produce definitc positive inotropic and chronotropic effects, even when given from outside the cell and which might prove to be a useful plarmacological tool.

\section{RLFERENCES}

1) Muneyama K., Bauer R.J., Shuman D.A. and Rohins R.K.: Biochemistry, N.Y. 10, 2390 (1971); 2) Postfriak TH., Suthfrland E.W. and Henion W.F.: Biochim. Biophys. Acta 65, 558 (1962); 3) Blechlr M. and Hlint N.H.: J. biol. (hem. 247, 7479 (1972); 4) Rall T.W. AND WeSt T.C.: J. Pharmacol. exp. Ther. 139, 269 (1963); 5) Imai S., Otoril T., Takrda K., KaIANO Y. AvD Horit D.: Japan. I. Phamacol. 24, 499 (1974) 